\title{
First Successful Therapeutic Plasma Exchange in a 3-Year-5-Month Old Bangladeshi Paediatric Patient: A Case Report
}

\author{
Tamanna Afroz ${ }^{1}$, Sabina Sultana ${ }^{2}$, Tangia Muquith ${ }^{3}$, Md. Mahbub Noor ${ }^{4}$, Mahfuz Ahmed Chowdhury ${ }^{4}$, \\ Quazi Smita $\mathrm{Haq}^{3}$, Abu Jafar Mohammed Saleh ${ }^{3 *}$ \\ ${ }^{1}$ Department of Transfusion Medicine, Evercare Hospital Dhaka, Bangladesh. \\ ${ }^{2}$ Department of Paediatric Nephrology, Evercare Hospital Dhaka, Bangladesh. \\ ${ }^{3}$ Department of Hematology and Stem Cell Transplant, Evercare Hospital Dhaka, Bangladesh. \\ ${ }^{4}$ Intensive Care Unit, Evercare Hospital Dhaka, Bangladesh.
}

Citation: Afroz T, Sultana S, Muquith T, Noor MM, Chowdhury MA, Haq QS, Saleh AJM. First Successful Therapeutic Plasma Exchange in a 3-Year-5-Month Old Bangladeshi Paediatric Patient: A Case Report. Haematol J Bangladesh 2020; 4 (1): 19-22.

DOI: http://doi.org/10.37545/haematoljbd 202055

Received: 05May 2020

Accepted: 16 May 2020

Published: 20 June 2020

*Correspondence: Abu Jafar Mohammed Saleh, Sr. Consultant, Haematology and Stem Cell Transplant, Evercare Hospital, Dhaka, Bangladesh. Contact: +880 1787 681748, email: ajmsaleh@gmail.com

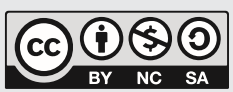

OPEN

ACCESS

Copyright: (C) 2020 by author(s). This is an open access article published under the Creative Commons Attribution-Non Commercial-No Derivatives 4.0 International License, which permits use, distribution and reproduction in any medium or format, provided the original work is properly cited, is not changed in any way and is not used for commercial purposes. http:// creativecommons.org/licenses /by/4.0/

indications, frequent technical problems regarding vascular access and lower blood volume, higher incidence of adverse events during the procedure and poor cooperation of the patient. ${ }^{3}$ Among paediatric nephrological diseases, aHUS is a leading clinical indication for TPE. 4

\section{Introduction}

\section{Case Report}

A three-year- five-month old boy weighing $15 \mathrm{~kg}$ diagnosed as aHUS at Dhaka Shishu Hospital who initially presented with diarrhoea with pneumonia. He had low complement (C3) level and underwent renal biopsy but formal report was missing. He received \begin{abstract}
Therapeutic plasma exchange (TPE) has evolved to an accepted therapy for
selected indications. The aim is to remove putative disease mediators from
the body. It is technically challenging in children but has become increasing-
ly common practices for last several decades. We report a successful case of
TPE along with renal replacement therapy in a 3-year-5-month old boy, ABSTRACT
Therapeutic plasma exchange (TPE) has evolved to an accepted therapy for
selected indications. The aim is to remove putative disease mediators from
the body. It is technically challenging in children but has become increasing-
ly common practices for last several decades. We report a successful case of
TPE along with renal replacement therapy in a 3-year-5-month old boy, ABSTRACT
Therapeutic plasma exchange (TPE) has evolved to an accepted therapy for
selected indications. The aim is to remove putative disease mediators from
the body. It is technically challenging in children but has become increasing-
ly common practices for last several decades. We report a successful case of
TPE along with renal replacement therapy in a 3-year-5-month old boy, ABSTRACT
Therapeutic plasma exchange (TPE) has evolved to an accepted therapy for
selected indications. The aim is to remove putative disease mediators from
the body. It is technically challenging in children but has become increasing-
ly common practices for last several decades. We report a successful case of
TPE along with renal replacement therapy in a 3-year-5-month old boy, ABSTRACT
Therapeutic plasma exchange (TPE) has evolved to an accepted therapy for
selected indications. The aim is to remove putative disease mediators from
the body. It is technically challenging in children but has become increasing-
ly common practices for last several decades. We report a successful case of
TPE along with renal replacement therapy in a 3-year-5-month old boy, ABSTRACT
Therapeutic plasma exchange (TPE) has evolved to an accepted therapy for
selected indications. The aim is to remove putative disease mediators from
the body. It is technically challenging in children but has become increasing-
ly common practices for last several decades. We report a successful case of
TPE along with renal replacement therapy in a 3-year-5-month old boy, To the best of our knowledge TPE and Haemodialysis for such age and weight was for the first time in Bangladesh.
\end{abstract}

Key words: Therapeutic Plasma Exchange (TPE), Atypical Haemolytic Uremic Syndrome (aHUS), Haemodialysis

TPE consists of drawing venous blood into the extracorporeal circuit, separating and removal of plasma from cellular component and return of all cellular components with appropriate replacement fluid (Albumin FP) to the patient. In clinical practice two rationales for TPE are to toxin) and to replace a deficient factor. One plasma volume (PV) exchange will remove around $65 \%$ of the initial component from intravascular space, 1.5 PV exchange around 75\% and $2 \mathrm{PV}$ around $83 \%{ }^{1}$ The American Society for Apheresis (ASFA) guideline is most widely followed and it provides evidence-based indications for TPE particularly for adults and automated apheresis machines are mostly used in adults. $^{2}$ Therefore, application of TPE in paediatric patients is more challenging for multiple factors: lack of universally accepted 
peritoneal dialysis but with rapid deterioration of his condition, the boy was referred to Apollo Hospitals Dhaka (now Evercare hospital Dhaka). He was found severely pale, lethargic and drowsy, with non-recordable BP, SPO2 $80 \%$ at room air; hepatomegaly, oozing from peritoneal dialysis catheter site, thrombophlebitis over right forearm and in septic shock at emergency. He was immediately transferred to ICU. CV line was placed, started nor-adrenaline and optimized antibiotics with Polymyxin B, Teicoplanin, Anidulafungin according to blood and urine culture report (Candida in blood and urine; Klebsiella in blood). His laboratory evaluation revealed very critical HB $2.4 \mathrm{gm} / \mathrm{L}$, platelet $10000 /$ micro litre, WBC 12000/micro litre, features of micro-angiopathic haemolyticanaemia in peripheral blood smear, a negative Coomb's test, LDH 2042 U/L, S. Haptoglobin $<29 \mathrm{mg} / \mathrm{dl}$, INR 1.84, APTT $38 \mathrm{sec}$, Fibrinogen $181 \mathrm{mg} / \mathrm{dl}$, Creatinine $2.9 \mathrm{mg} / \mathrm{dl}$, Urea 174, Bilirubin $0.5 \mathrm{mg} / \mathrm{dl}$, ADAMTS13 was not done. His procalcitonin was $>200 \mathrm{ng} / \mathrm{ml}$. Patient was managed by PRBC and one aphaeretic unit platelet was transfused before the insertion of Femoral catheter. On next day urgent decision of TPE was taken.

One session of TPE was initiated in ICU using Optia Apheresis (Terumo BCT, Lakewood, CO, USA) machine. His total blood volume (TBV) was $1275 \mathrm{ml}$ with plasma volume (PV) of $730 \mathrm{ml}$. His extra corporeal volume (ECV) was exceeding $10 \%$ from his TBV and intra procedural haematocrit below $24 \%$ during the session. So, we performed custom prime with PRBC before connecting the circuit to the patient. Throughout the session his vitals were monitored carefully. To avoid systemic hypocalcaemia, calcium gluconate injection was given accordingly. Fluid balance was kept at $90 \%$ to keep the patient at negative balance for renal impairment. Fresh frozen plasma (FFP) and normal saline were used as replacement fluids. One volume of plasma exchange was done successfully without any complications.

He had single session of haemodialysis on the following day. He was also started prednisolone and mycophenolate mofetil. His renal function started to improve gradually Patient's clinical, haematological and renal conditions responded dramatically well after TPE with haemodialysis and more TPE sessions were planned but patient couldn't continue due to financial ground. His hospital stay was complicated with hypertension requiring antihypertensive. With other supportive treatments patient was improved and was discharged on 17 th day.

\section{Discussion}

Atypical HUS is a rare clinical condition which is associated with significant morbidity and mortality. ${ }^{5,6}$ Classical presentation of aHUS is the triad of thrombocytopenia, microangiopathic haemolyticanaemia, and acute renal failure. ${ }^{7}$ Our patient presented in this manner. Atypical HUS is a multigenic complement-mediated disorder. ${ }^{7}$ It is often associated with a genetic or acquired defect, resulting in host cell dysregulation of complement. In many patients, a gastrointestinal or a urogenital infection pave the way for the clinical triad and leads to aHUS. ${ }^{8}$ In complement-mediated HUS mutations in the complement factor $\mathrm{H}(\mathrm{CFH})$ gene that encodes regulatory proteins are commonly found genetic abnormalities. ${ }^{9,10}$ This condition often most commonly inflicts females and children. Current therapeutic options for aHUS are plasma exchange and eculizumab (anti C5 antibody). Empirically, TPE is considered as the first-line treatment. Although TPE is associated with a reduction of mortality from $50 \%$ to $25 \%$, in a 3 -year follow-up, $48 \%$ of paediatric patients and $67 \%$ of adult patients died or progressed to ESRF. $6,11,12$ TPE in combination with immunosuppressive drugs such as corticosteroids and azathioprine or mycophenolate mofetil and an anti-CD20 antibody (rituximab) has shown long-term dialysis-free survival in $60-70 \%$ of pa-tients. ${ }^{13,14}$

Eculizumab is recommended as the first-line therapy for children. ${ }^{15}$ However, when eculizumab is unavailable in resource-poor settings such as Bangladesh, TPE may be the first treatment of choice. In our patient, TPE was a successful treatment, because he completely recovered following TPE with prednisolone. ASFA assigns TPE in aHUS in category I.

Since last few decades TPE has been successfully used in various paediatric neurologic, immunologic, renal and haematological conditions. First plasma exchange was reported in patient of Wald Enstrom's Macroglobulinemia in 1960. ${ }^{16}$ Modern Apheresis instruments are fully auto-mated and separation can be done on basis of density, size or differential adsorptions.

Paediatric patients are considered special and attention should be given to access, anticoagulation, volume shifts and replacement fluid. Continuous centrifugation is generally considered preferable to intermittent centrifugation for children. The large ECV, which is fixed in automated apheresis instrument and blood loss in the circuit, increase the risk of hypotension and anaemia. ${ }^{17}$ At the beginning of the procedure the blood volume removed acutely from the patient is the equivalent to the volume of the circuit including tubing and centrifuge. Also, an obligatory red cell mass is retained in the channel throughout the procedure to allow separation of blood component. ${ }^{18}$ This obligatory ECV can represent a significant percentage of patient's TBV and it ranges 
from $200-400 \mathrm{ml}$ in different apheresis instruments. ${ }^{19}$ If ECV exceeds 10-15\% (In paediatricpatient usually $8-10 \%$ ) of patient's TBV it can cause hypotension and impaired oxygen delivery. ${ }^{20}$ To avoid this complication the circuit can be primed with PRBC or albumin. Successful TPE can be done safely in children weighing as little as $3.2 \mathrm{~kg}$ after blood priming. ${ }^{21}$ Another challenge for paediatric population is the vascular access. Under standard draw negative pressure, the catheters should be stiff and should not collapse. Carter et al reported catheter related complications were common in paediatric population. ${ }^{22}$ Large bore, dual lumen catheters which are used for haemodialysis can be used and proper care should be taken to prevent infections and clotting. ${ }^{23}$ Michon et al found complications are relatively less $(<6 \%)$ and minor in adults, where as it is up to $55 \%$ procedures in children. ${ }^{24}$ The most common complication was hypotension (14\%) but only $<5 \%$ required fluid bolus. ${ }^{24} \mathrm{ECV}$ was exceeding $>15 \%$ of TBV in our patient. So, we needed to prime the circuit with PRBC. Patient responded well after one session.

\section{Conclusion}

TPE is safe and highly effective therapy in paediatric patients when volume shifts, calcium supplementation, venous access, anticoagulation, and psychological aspects are taken care of properly.

\section{References}

1. Bobati SS, Naik KR. Therapeutic plasma exchange-An emerging treatment modality in patients with neurologic and non-neurologic diseases. Journal of clinical and diagnostic research: JCDR. 2017 Aug;11(8):EC35. Doi: 10.7860/JCDR/2017/27073.10480. Epub 2017 Aug.

2. Schwartz J, Padmanabhan A, Aqui N, Balogun RA, Connelly- Smith L, Delaney M, et al. Guide-lines on the Use of Therapeutic Apheresis in Clinical Practice-Evidence-Based Approach from the Writ-ing Committee of the American Society for Aphere-sis: The Seventh Special Issue. J Clin Apher. 2016 Jun;31(3):149-162. doi: 10.1002/jca.21470.

3. Özkale M, Erol I, Özkale Y, Kozanoğlu İ. Overview of therapeutic plasma exchange in pediatric neurology: a single-center experience. Acta Neu-rologicaBelgica. 2018 Sep 1;118(3):451-458. DoI: https://doi.org/ 10.1007/s13760-018-09610965

4. Hans R, Sharma RR, Marwaha N, Suri D, Kumar R, Gupta A, Singh S. Efficac and safety of therapeu -tic plasma exchange by using apheresis devices in pediatric atypical hemolytic uremic syndrome pa-tients. Journal of clinical apheresis. 2016 Aug; 31(4):381-387.doi: 10.1002/jca.21412. Epub 2015 Jul 25.
5. Fremeaux-Bacchi V, Fakhouri F, Garnier A, Bi-enaimé F, Dragon-Durey MA, Ngo S, Moulin B, Servais A, Provot F, Rostaing L, Burtey S. Genetics and outcome of atypical hemolytic uremic syndrome: a nationwide French series comparing children and adults. Clinical Journal of the American Society of Nephrology. 2013 Apr 5;8(4):554-562.

6. Noris M, Caprioli J, Bresin E, Mossali C, Pianetti G, Gamba S, Daina E, Fenili C, Castelletti F, Sorosina A, Piras R. Relative role of genetic complement abnormalities in sporadic and familial aHUS and their impact on clinical phenotype. Clinical Journal of the American Society of Nephrology. 2010 Oct 1;5(10): 1844-1859.

7. Noris M, Remuzzi G. Hemolytic uremic syndrome. Journal of the American Society of Nephrology. 2005 Apr 1;16(4):1035-1050.

8. Nester CM, Barbour T, de Cordoba SR, Dragon- Durey MA, Fremeaux-Bacchi V, Goodship TH, Kavanagh D, Noris M, Pickering M, Sanchez- Corral P, Skerka C. Atypical aHUS: state of the art. Molecular immunology. 2015 Sep 1;67(1):31-42. Doi: 10.1016/j.molimm. 2015.03.246.

9. Waters AM, Licht $\mathrm{C}$. aHUS caused by complement dysregulation: new therapies on the horizon. Pediatric Nephrology. 2011 Jan 1;26(1):41-57. doi:10.1007/s00467-010-1556-4.

10. Monteferrante CJ, Liszewski MK, Kavanagh D, Atkinson JP, Remuzzi G, Mele C, Bresin E, Cassis L, Gamba S, Porrati F, Bucchioni S. MCP, CFH Genetics of HUS: the impact of MCP, $\mathrm{CFH}$ and IF muta-tions on clinical presentation, response to treatment, and outcome. Blood. 2006 April. doi: 10.1182/blood2005-10-007252.

11. Ariceta G, Besbas N, Johnson S, Karpman D, Landau D, Licht C, Loirat C, Pecoraro C, Taylor CM, Van de Kar N, Vande Walle J.Guideline for the investigation and initial therapy of diarrhea-negative hemolytic uremic syndrome. Pediatric nephrology. 2009 Apr 1;24(4):687.

12. Michael M, Elliott EJ, Craig JC, Ridley G, Hodson EM. Interventions for hemolytic uremic syndrome and thrombotic thrombocytopenic purpura: a systematic review of randomized controlled trials. American Journal of Kidney Diseases. 2009 Feb 1;53(2): 259-272.

13. Noris M, Remuzzi G. Atypical hemolytic-uremic syndrome. New England Journal of Medicine. 2009 Oct 22;361(17):1676-1687.

14. Kwon T, Dragon-Durey MA, Macher MA, Bau- douin V, Maisin A, Peuchmaur M, Fremeaux- Bacchi V, Loirat C. Successful pre-transplant management of a patient with anti-factor $\mathrm{H}$ autoantibodies-associated haemolytic uraemic syndrome. Nephrology Dialysis Transplantation. 2008 Jun 1;23(6):2088-2090.

15. Loirat C, Fakhouri F, Ariceta G, Besbas N, Bitzan M, Bjerre A, Coppo R, Emma F, Johnson S, Karpman D, Landau D. An international consensus approach to the management of atypical hemolytic uremic syndrome in children. Pediatric nephrology. 2016 Jan 1;31(1):15-39. 
16. Schwab PJ, Fahey JL. Treatment of Walden-ström's macroglobulinemia by plasmapheresis. New England Journal of Medicine. 1960 Sep 22;263(12):574-579.

17. Reddy SK, Jahan A, Chaturvedi S, Agarwal I. Plasma exchange for paediatric kidney disease-indications and outcomes: a single- centre experience. Clinical kidney journal. 2015 Dec 1;8(6):702-707.doi: 10.1093/ckj/sfv084 .

18. Carter CE, Benador NM. Therapeutic plasma exchange for the treatment of pediatric renal diseases in 2013. Pediatric Nephrology. 2014 Jan 1;29(1):35-50. Doi: https://doi.org/10.1007/ s00467013-2479-7

19. Goldstein SL, Klaus G, Friedman DF, Kim HC. Paediatric therapeutic apheresis. In: Warady editor. Paediatric dialysis. Springer, New York, 2012.p. 775-796.

20. Greenstein SM, Delrio M, Ong E, Feuerstein D, Schechner R, Kim D, Corey H, Kaskel R, Tellis VA, Moritz ML. Plasmapheresis treatment for recurrent focal sclerosis in pediatric renal allografts. Pediatric Nephrology. 2000 Sep 1;14(12):1061-1065.
21. Jung S, Kang ES, Ki CS, Kim DW, Paik KH, Chang YS (2011) Successful therapeutic plasma ex-change in a $3.2-\mathrm{kg}$ body weight neonate with atypical haemolytic uremic syndrome. J Clin Apher 26:162-165.

22. Jung S, Kang ES, Ki CS, Kim DW, Paik KH, Chang YS. Successful therapeutic plasma exchange in a $3.2-\mathrm{kg}$ body weight neonate with atypical hemolytic uremic syndrome. Journal of clinical apheresis. 2011;26(3):162-165.

23. Kim HC. Therapeutic pediatric apheresis. Journal of Clinical Apheresis: The Official Journal of the American Society for Apheresis. 2000;15(1-2): 129-157.

24. Michon B, Moghrabi A, Winikoff R, Barrette S, Bernstein ML, Champagne J, David M, Duval M, Hume HA, Robitaille N, Bélisle A. Complications of apheresis in children. Transfusion. 2007 Oct;47(10):1837-1842. 